\title{
Urban vegetable for food security in cities. A review
}

\author{
Christine Eigenbrod $•$ Nazim Gruda
}

Accepted: 20 November 2014 / Published online: 11 December 2014

(C) INRA and Springer-Verlag France 2014

\begin{abstract}
Global food production faces great challenges in the future. With a future world population of 9.6 billion by 2050 , rising urbanization, decreasing arable land, and weather extremes due to climate change, global agriculture is under pressure. While today over $50 \%$ of the world population live in cities, by 2030 , the number will rise to $70 \%$. In addition, global emissions have to be kept in mind. Currently, agriculture accounts for around $20-30 \%$ of global greenhouse gas emissions. Shifting food production to locations with high demands reduces emissions and mitigates climate change. Urban horticulture increases global food production by exploiting new locations for cultivation. However, higher land prices and urban pollution constrain urban horticulture. In this paper, we review different urban cultivation systems throughout the world. Our main findings from ecological, economical, and social aspects are: (1) Urban horticulture activities are increasing globally with at least 100 million people involved worldwide. With potential yields of up to $50 \mathrm{~kg} \mathrm{per} \mathrm{\textrm {m } ^ { 2 }}$ per year and more, vegetable production is the most significant component of urban food production which contributes to global food security. (2) Organoponic and other low-input systems will continue to play an important role for a sustainable and secure food production in the future. (3) Despite the resource efficiency of indoor farming systems, they are still very expensive. (4) Integrating urban horticulture into educational and social programs improves nutrition and food security. Overlaying these, new technologies in horticultural research need to be adopted for urban horticulture to increase future efficiency and productivity. To enhance sustainability, urban horticulture has to be integrated into the urban planning process and supported through policies. However, future food production should not be "local at any price," but rather committed to increase sustainability.
\end{abstract}

C. Eigenbrod $(\bowtie) \cdot$ N. Gruda

Institute of Plant Sciences and Resource Conservation, Division of

Horticultural Sciences, University of Bonn, Bonn, Germany

e-mail: ChristineEigebrod@gmail.com
Keywords Climate change · Sustainable food · Sky farming · Urban population $\cdot$ Vertical farming $\cdot$ Urban agriculture $\cdot$

Urban gardening

Contents

1. Introduction. . . . . . . . . . . . . . . . . . . .

2. Urban agriculture.

2.1. Definition of urban agriculture and the importance of urban horticulture. . . . . . . . . . . . . . . .

3. Traditional growing systems. ...............

3.1. Home gardening. .....................

3.2. Community gardening. ..................

3.3. Continuous productive urban landscapes.......

4. Innovative cropping systems. ................

4.1. Soilless cultures. ......................

4.2. Organoponics........................

5. Indoor farming systems. . . . . . . . . . . . . .

5.1. Building integrated agriculture. . . . . . . . . . .

5.2. Vertical farming. . . . . . . . . . . . . . . . .

5.3. New technologies for indoor farming. . . . . . . .

6. Features of urban horticulture. . . . . . . . . . . . . .

6.1. Food security.

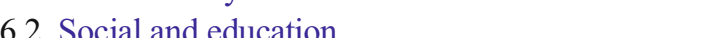

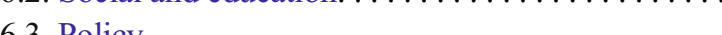

6.4. Environmental factors and climate change.....

6.5. Self-sufficiency of cities. . . . . . . . . . . . .

7. Discussion. . . . . . . . . . . . . . . . . . . . . .

8. Conclusion. . . . . . . . . . . . . . . . . . . . . . . .

9. Acknowledgments. . . . . . . . . . . . . . . .

10. References. .......................... 


\section{Introduction}

In a time of extremely high population growth, loss of arable land, dietary changes, increasing bioenergy use, and climate change, the food issue is becoming more and more important (Foley et al. 2011). According to the United Nations (2013), the current world population of 7.2 billion people will increase to 9.6 billion people by 2050 . A growing population is, however, not the only problem humanity has to face. Even today, approximately a billion people are chronically malnourished (Foley et al. 2011), and, in addition, the stability of the whole food systems may be at risk because of short-term variability in supply due to climate change (Wheeler and von Braun 2013).

Moreover, Foley et al. (2011) reported that the world's croplands and pastures expanded by about $3 \%$ between 1985 and 2005 (FAOSTAT 2013). This slow net increase includes significant expansion in some areas, e.g., the tropics, as well as little change or a decrease in others, e.g., the temperate zone. The rate of cropland is increasing by only $2.41 \%$ (Foley et al. 2011). However, between 2005 and 2011, no increase, but rather a decrease of $0.19 \%$ was found in the agricultural area, although the cultivated area with vegetables including melons had generally increased by approximately $9.1 \%$ (FAOSTAT 2013).

Much of the current degraded land worldwide is lost to erosion and human activities, and it is difficult and expensive to exploit new land for agricultural use (Godfray et al. 2010). Some types of erosion are caused by wind and water, others by salinization and desertification. Erosion by water accounts for $56 \%$, and erosion by wind accounts for $28 \%$ of degraded land worldwide. With $27 \%$ of degradation being due to agricultural activities and $34 \%$ due to overgrazing, agriculture plays an important role in the loss of arable land. Additionally, weather extremes will worsen in the next 50 years due to climate change, which could reduce yields by 13-45\% (UNCCD 2012). Other reasons for the loss of arable land are sealing, urbanization, and the rise of sea levels. Agriculture is not only prone to climate change, but also one of the major contributors. It is assumed that $20-30 \%$ of the global greenhouse gas emissions are caused by food production (Kulak et al. 2013).

Studies of common crop groups, including cereals, oilseeds, fruits, and vegetables, suggest that crop production increased by $47 \%$ between 1985 and 2005 . However, taking into account the increase in harvested land, Foley et al. (2011) showed that average global crop yields increased by only $20 \%$ between 1985 and 2005. For vegetables, an increase of $26.4 \%$ was calculated for this time; between 2005 and 2011, the yield increase was just $10.7 \%$.

According to Foley et al. (2011), to achieve global food security and environmental sustainability, agricultural systems must be transformed to address the challenges of food production and environmental protection. Therefore, the authors recommended four strategies: (1) cease the expansion of agriculture, particularly that into tropical forests; (2) close yield gaps in underperforming landscapes where yields are currently below average; (3) increase agricultural resource efficiency of water, nutrients, and other agricultural measures; and (4) increase food delivery by changing diets and reducing waste.

In addition to an analysis of crop area and production, some new demographic development has to be taken into account. Worldwide urbanization is increasing rapidly, especially in developing countries representing a rate of $3.6 \%$ per year from 1950 until 2005 compared with industrialized countries which only had a growth rate of $1.4 \%$ (Aubry et al. 2012). In 2008, the global urban population overtook the rural population for the first time in history. In 2007, 3.3 billion people lived in cities, but the world's urban population is expected to double to 6.4 billion by 2050 . According to Dubbeling et al. (2010), by $2030,60 \%$ of the world's urban population will live in cities, whereas Bakker et al. (2000) predict that in developing countries, up to $80 \%$ of the population could live in cities by 2025 .

The number of mega cities will also rise rapidly. By 2025, 12 of the 15 largest cities in the world will be located in Asia (Nugent 2000). Today, for a mega city with 10 million people or more, over 6,000 tons of food has to be imported every day (Drescher et al. 2005). London, with its 8 million residents and surface area of $1,600 \mathrm{~km}^{2}$ "requires the equivalent of $40 \%$ of Britain's entire productive land for its food" (Deelstra and Girardet 2000).

According to Shackleton et al. (2009), more than $56 \%$ of the world's poor are concentrated in cities or urban areas. The importance and urgency of urban agriculture is clear as rising urban poverty is often followed by increasing malnutrition and food insecurity (Dubbeling et al. 2010).

One of the most important challenges of the future will be the further development of rural areas. The food production in these, as well as in other already established areas, will still remain the main activity. However, in order to produce enough food in the future, vacant spaces in cities should also be considered as possible locations in order to take pressure from rural agriculture and to decompensate land loss. By turning vacant lots into urban vegetable gardens, food security and sustainability are increased. However, it is important not to lay the focus too strong on highly populated urban areas with limited space. Shifting the cultivation to peri-urban areas can be more reasonable in some cases. Also, urban agriculture does not only have positive effects in densely populated areas, it also benefits undersupplied suburbs which can be in greater need of local food supply than city centers, e.g., in Detroit, United States of America (Fig. 1). Detroit is characterized by its decay, and the high numbers of vacant lots and unemployment. 


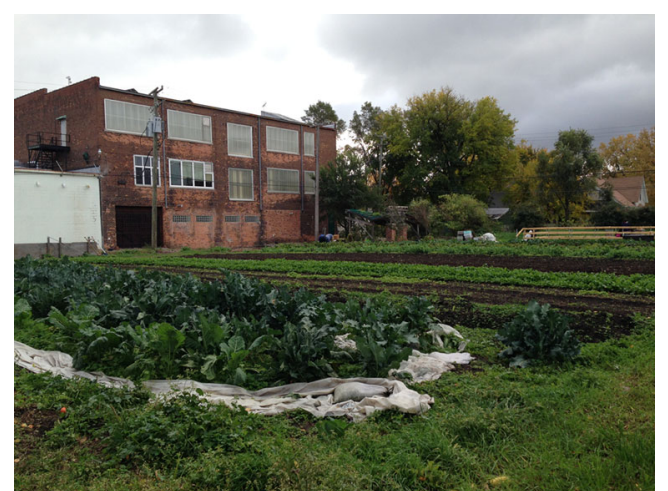

Fig. 1 This picture shows an urban farm in Detroit next to an abandoned building. The farm contributes to a greener and more engaged neighborhood and supplies fresh vegetables to local people. Additionally, the collective gardening strengthens communities and engages people in outdoor activities (Figure: Eigenbrod, 2014, private collection)

In order to utilize these vacant urban spaces as efficiently as possible, new cultivation methods are required. This paper will demonstrate the possibilities for urban vegetable cultivation, the kind of technologies which still need to be developed, and their importance in sustainably guaranteeing food security in cities in the future.

\section{Urban agriculture}

2.1 Definition of urban agriculture and the importance of urban horticulture

Urban agriculture "is an industry located within a town, a city or metropolis, which grows or raises, processes and distributes a diversity of food and non-food products (re-)using largely human and material resources, products and services found in and around that urban area, and in turn supplying human and material resources, products and services largely to that urban area" (Mougeot 2000).

The main characteristics by which different methods of urban agriculture can be classified are the types of actors involved, the location of production, the products, the scale of production and technology, the types of economic activities involved, and the degree of market orientation (Dubbeling et al. 2010).

Cultivation area and the amount of people involved in urban farming have never been higher than today. Smit et al. (1996) estimated that about 800 million people were engaged in urban agriculture and that 200 millions of these were market producers. These data are, however, according to Orsini et al. (2013) likely overestimated, since they were mainly derived from estimates by the Urban Agriculture Network based on individual experiences and observations and extrapolation from data. The Food and Agriculture Organization, for instance, evaluates in a more conservative way that 100 million people are estimated to earn parts of their income directly from urban farming (FAO 1996). As well as providing the urban poor with nutritious food and extra income, urban and peri-urban agriculture have become key parts of strategies for reducing cities' ecological footprint, recycling urban wastes, containing urban sprawl, protecting biodiversity, building resilience to climate change, stimulating regional economies, and reducing dependency on global food markets (FAO 2014).

McClintock (2010) recently attempted to theorize the increasing interest in urban agriculture. He names the alienation from our natural environment caused by urbanization and capitalism as possible main reasons for a broader adoption of urban agriculture nowadays.

The increasing urbanization causes a shift in the demand for food to cities. In addition, the desire for more sustainable, self-sufficient and greener cities is growing especially in developed countries. While in developing countries urban agriculture is mainly a method for producing food, in developed countries, urban farming is also seen as recreation or used for educational functions (Dubbeling et al. 2010). The low carbon footprint and the greater transparency of food production mirror the modern urban lifestyle and make urban agriculture particularly interesting (Specht et al. 2013). However, its contribution to economy should not be underestimated (Mok et al. 2014). According to Orsini et al. (2013), urban agriculture represents an opportunity for improving food supply, health conditions, local economy, social integration, and environmental sustainability altogether.

According to Mok et al. (2014), food production in cities has long been a tradition in many countries around the world, playing an important role considering food security and social well-being. One of the main benefits of urban agriculture worldwide is the production of horticultural goods. According to Orsini et al. (2013), urban horticulture is the most competitive branch of urban farming. Due to the high cost of urban land, vegetables with their high water and fertilizer efficiency are more profitable than growing other crops. They further have the advantage of having a special nutritional value and that no further processing after harvest is needed. As vegetables have a very short cycle, they can supply growing demands very quickly. For example, after a catastrophe, some vegetable species can be harvested just 60-90 days after sowing and when cultivated with seedlings, even less (Dubbeling et al. 2010). This makes urban horticulture a relatively quick responsive system especially after a breakdown of the food supply chains through trade isolation as seen in Cuba (Hamilton et al. 2013).

Dubbeling et al. (2010) and Orsini et al. (2013) report an achievable yield of up to $50 \mathrm{~kg}$ a year on only $1 \mathrm{~m}^{2}$ with fruit and vegetable cultivation. In comparison to other crops, this is a very high yield. As Hamilton et al. (2013) reported, the 
amount of land currently used for global cereal production in developing countries is approximately ten times the land occupied by cities worldwide, whereas global vegetable and fruit production each cover an area roughly equivalent to that of cities. This leads to the assumption that vegetables are suitable for urban cultivation, both for high-tech equipment as well as for the self-supply of poor urban residents, and that urban horticulture has the potential of a certain degree of selfsufficiency.

Urban horticulture activities are increasing globally with at least 100 million people involved worldwide. With potential yields of up to $50 \mathrm{~kg}$ per $\mathrm{m}^{2}$ per year and more, vegetable production is the most significant component of urban food production which contributes to global food security.

\section{Traditional growing systems}

Globally, there are various approaches of urban horticulture such as allotments for self-consumption, large-scale commercial farms, community gardens, and even edible landscapes. There are lots of vacant spaces which can be used for urban horticulture such as rooftops, fallow land, and smaller areas like roadsides or private balconies. The availability of fresh, healthy, and cheap food is a major reason to engage in urban horticulture. Locally produced food is usually fresher and more nutritious than imported food and therefore has the potential to increase the overall food intake and improve nutrition. This is of particular importance for household members with special nutritional needs, for example, the elderly or small children, especially in developing countries (Dubbeling et al. 2010).

\subsection{Home gardening}

Home gardening is a worldwide popular phenomenon through all levels of society and is the most common form of urban agriculture (de Neergard et al. 2009). Proximity to the home of the growers, the cultivation of various vegetables, and the use of low-cost inputs are generally considered fundamental characteristics of home gardens. The production is usually more supplementary than being the main source for the consumption (Galhena et al. 2013). The most important benefits are the supply of fresh vegetables, savings on food expenses, and extra income if a surplus of vegetables is sold (Oluoch et al. 2009).

This type of urban horticulture is seen by many people as a hobby and an opportunity to spend time outdoors (Lovell 2010). However, in developing countries, self-sufficiency through urban horticulture can be vital for a family's survival. The world's poorest live in urban areas of developing countries. These families spend up to $60-80 \%$ of their income on food (Nugent 2000). Enabling urban poor to produce their own food would allow them to save a great amount of money. However, Nugent (2000) reports that poor families engaging in urban horticulture often fail at being sufficiently supplied with food. De Zeeuw et al. (2000) claim that the reason for this is the lack of access to adequate amounts of land. Therefore, urban horticulture is less significant for the poorest as they usually have little or no access to land (de Neergard et al. 2009). In developed countries like the United States of America and the UK, home gardening can also decrease the risk of obesity and unhealthy diets. Bohn and Viljoen (2011) report that both the quantity and the quality of fruit and vegetable uptake were increased significantly by home gardening activities.

To achieve sufficient yields and a healthy produce, adequate and sufficient irrigation is necessary. Source for this can be rain, harvested water, tap-water, or wastewater. Especially in Africa, wastewater is often used for irrigation because of its great benefits such as accessibility and permanent supply. Using untreated wastewater can pose a great risk to human health, and unfortunately, modern treatment technology remains too expensive for poor farmers (Hamilton et al. 2013). If used untreated or inadequately treated, epidemics can be caused by eating the contaminated food (Mbaye and Moustier 2000). In tropical climates, irrigated urban agriculture even increases the risk of malaria if mosquito larvae are able to breed in stagnant water (Hamilton et al. 2013).

\subsection{Community gardening}

Community gardening means a collective cultivation of plants by various people on a shared area. The garden organizations range from very close-knit associations with mutual activities to loosely organized ones which only share the facilities (de Neergard et al. 2009). The close-knit associations which act on a larger scale often have small shops or cafés where self grown products are sold. Community gardens also differ in the way they are cultivated. Some gardens do not have any private vegetable patches but are completely cultivated on a collective base.

The shared areas of community gardens are mostly urban open spaces. These can be roof-tops and other fallow land in a city and range from small plots to larger areas. Limited access to land, lack of tenure on property, and insufficient infrastructure and services for urban growers are among the main restrictions of urban horticulture according to Lovell (2010). Community gardens can be either supported through nongovernmental organizations, municipalities, or financed through a private sponsor or various donors. In other gardens, individuals or groups own or rent a private patch and share the facilities with the other gardeners. Vegetables can be cultivated in mobile containers such as boxes (Fig. 2) or rice sacks. In this way, unusual areas can also be exploited, and there is no 


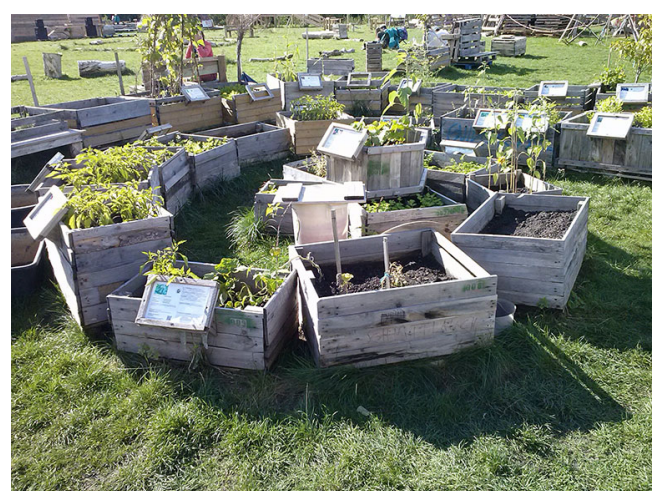

Fig. 2 Vegetables in mobile containers at the former Tempelhof Airport in Berlin. Using mobile containers such as boxes makes it possible to exploit unusual areas. This is a simple form of plant cultivation in a "growing media" that theoretically could be applied everywhere. This also includes closed-up or asphalt areas of the city, e.g., in city squares or terraces. This way, there is no risk of plants becoming contaminated by polluted soil (Figure: Gruda, 2013, private collection)

risk of plants becoming contaminated through polluted soil. This is a simple form of plant cultivation in "growing media" that theoretically could be applied everywhere. This means in closed-up or cemented areas of the city such as city squares or terraces.

Community gardens exist all over the world in both developing and industrialized countries. The big differences between the gardens in the various countries lie in the way and the reasons the gardens were created. In developing countries, the matter of food security plays an important role, and community gardens are often established because of poverty and necessity. Through community gardens, residents have the opportunity to use shared or subsidized land and thus enhance their nutrition. Many cities in, for example, Sri Lanka, Argentina, and Madagascar, promote school garden programs. These programs are designed to provide young students with fresh and healthy food education and play an important role in terms of nutrition and food security (Dubbeling et al. 2010).

In industrialized countries, such gardens are often established because of the desire for a greener city and a meaningful activity. There, the social and educational benefits predominate. The intended goal is to strengthen the gardener's community, to be active in nature and to establish a feeling of responsibility through the cultivation of plants, mostly vegetables. In this way, agricultural activities do not only serve to supplement food supply, but also provide a platform for intercultural communication and for a strengthened community (Lovell 2010). However, in certain American cities called "food deserts," it is difficult to buy fresh fruit and vegetables in local stores. In order to give locals access to healthy and fresh food, community gardens can increase the local supply and while strengthening the community (Lovell 2010; Metcalf and Widener 2011).

\subsection{Continuous productive urban landscapes}

Continuous Productive Urban Landscapes, or "edible cities," are holistic approaches of making urban infrastructures more sustainable by integrating urban horticulture, green corridors, and areas for leisure outdoor activities into cities' infrastructures as essential elements (Bohn and Viljoen 2011). This would make the city environmentally more sustainable and would also improve its social and economic performance. The intention is to improve the overall character of the city and connect it to the rural area (Lovell 2010). Within Continuous Productive Urban Landscapes, cultivation practices usually range from small-scale gardening to high-yield commercial gardening (Bohn and Viljoen 2011). In order to implement it in cities without a lot of vacant land, infrequently used roads could be converted into a Continuous Productive Urban Landscapes green space with enough space for a pedestrian and bicycle path (Bohn and Viljoen 2011).

The Incredible edible Todmorden is a town in Yorkshire, England, and was the first city of its kind (Bohn and Viljoen 2011). Throughout the town, at different public spaces, both visitors and residents can pick vegetables and fruits. This pioneering project stimulated various cities such as Andernach, Germany (Fig. 3), and Brussels, Belgium (Bohn and Viljoen 2011).

Under the label "eatable city," Brussels presents a very informative and multifaceted project (Fig. 4). In the city center, close to the central train station, the first eatable park was created in 2013. Vegetables grace the city everywhere and human-sized pots are placed on the sides of streets. The motive is to engage people in food production and to create a sustainable and environmentally friendly city.

\section{Innovative cropping systems}

Low soil quality and water availability, the need for yield maximization, and reducing environmental impact are still current issues in horticultural production. New cropping technologies have been developed in order to address these issues and make horticulture more sustainable. These cultivation systems are very intensive and are usually found in urban areas with limited cultivation space (Orsini et al. 2013).

\subsection{Soilless cultures}

The term "soilless culture" is defined as the cultivation of plants in systems without soil "in situ." In recent years, a multitude of innovative cultivation procedures using bags, mats, and containers, in addition to nutrient solutions, have been developed. These cultivation methods include systems without a solid medium, as well as aggregate systems, in 
Fig. 3 Vegetables in the city of Andernach, Germany. Vegetables are cultivated in green spaces all over the old city for residents. Everyone can cut vegetables for self consumption, cooking, or preparing a fresh salad. Another characteristic is that some old vegetable varieties, the so-called forgotten varieties are cultivated in this area (Figures: Gruda 2014, private collection)
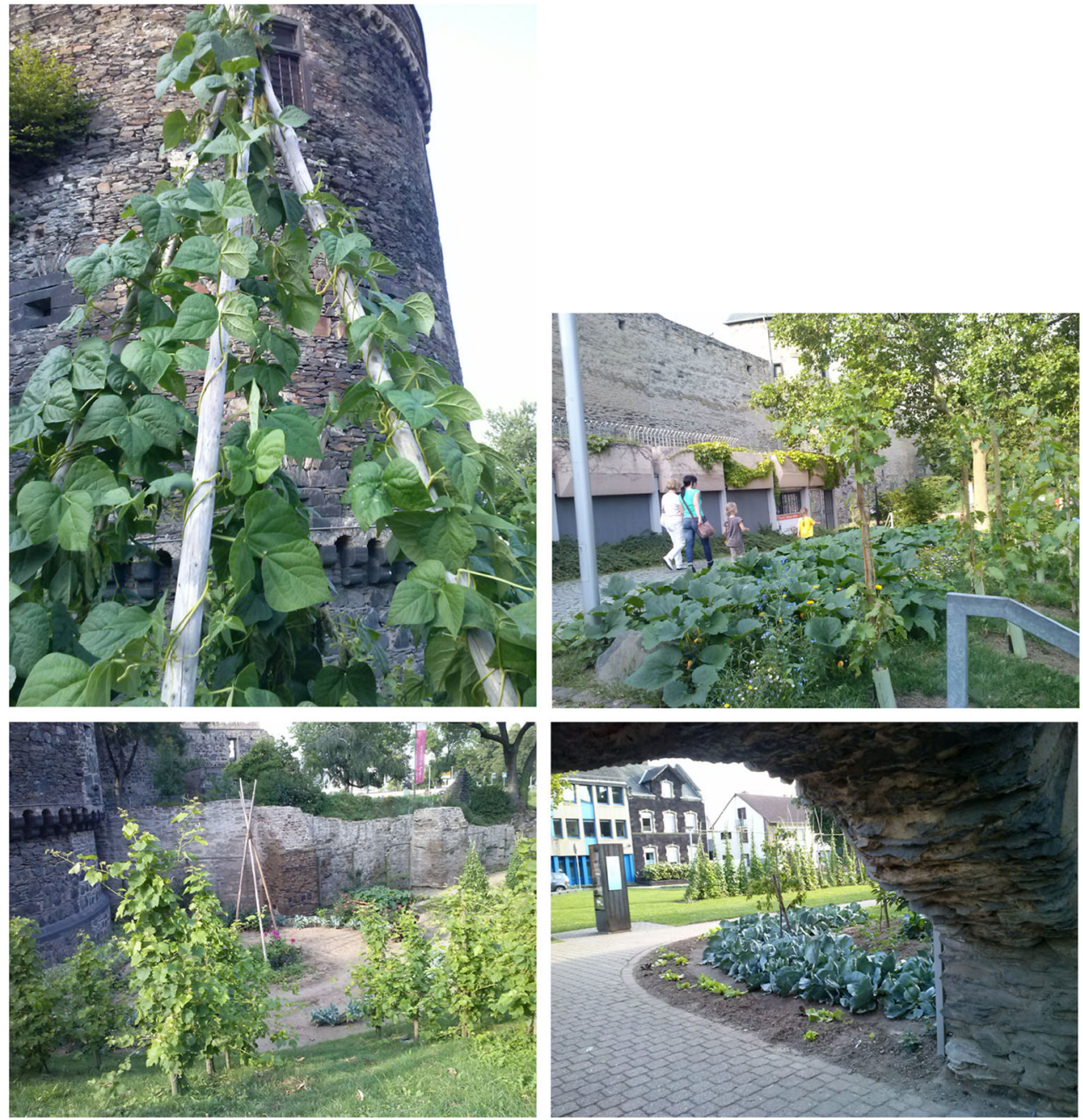

which inorganic or organic substrates are used (Gruda 2009; Gruda et al. 2007; Gruda and Tanny 2014). In addition, Gruda $(2005,2009)$ reported that an adaptation of cultural management to the specific cultural system of soilless culture, as well as crop demand, can further result in an improvement of the quality of horticultural products.

With the steady increase of soil erosion and the loss of arable land, the importance of soilless cultures is likely to increase in the near future. Because of their light weight and their sustainability in terms of resource efficiency, soilless systems are especially suitable for urban areas. In hydroponic systems, vegetables are grown in water which contains minerals and nutrients needed by the plants. This makes an exact dosage and application of nutrients possible. Interestingly, hydroponics as well as urban agriculture in general, have their roots in times of crises (Savvas and Passam 2002; Mok et al. 2014). Wartime gardening was promoted as a way to increase food security in the United States of America during World Wars I and II. Hydroponic systems were used to some extent by the United States Army to produce vegetables for both soldiers and civilians in some non-arable islands in the Pacific which were contaminated due to war operations (Jones 1982; Savvas and Passam 2002; Mok et al. 2014).

Aquaponic systems consist of a hydroponic unit cultivating vegetables and an aquaculture unit. The waste water from a fish tank runs through the hydroponics, and parts of fish excrements are removed from the tank to serve as nutrients for the plants. The water is treated and then flows back to the fish tank to be reused. This production type allows a simultaneous production of both vegetable and fish with the same water and nutrient cycle. This feature makes this production type very sustainable in terms of nutrient and water recycling. In this way, farmers can save money and effort on fertilizing plants (Savidov et al. 2007). For an implementation in urban areas, the weight of the system is particularly important and could be a disadvantage, for instance, concerning an installation on a rooftop. However, since fish do not require natural light, the water tanks could be installed inside a building and a greenhouse with the hydroponic unit could be installed on the roof.

Efficiency does not always go hand in hand with modern technology. Simpler technologies in developing countries, such as simplified hydroponics, extensively diffused in 
Fig. 4 Under the label "eatable city," Brussels presents a very informative and multifaceted project. In the city center, close to the central train station, the first eatable park was created in 2013. Vegetables grace the city everywhere, and human-sized pots are placed on the sides of streets. A call for more responsibility can be seen on the picture: "take over your window sills, balconies, and gardens ..." The motive in all these actions is to engage people in food production and to create a sustainable and environmentally friendly city (Figures: Gruda, 2013, private collection)
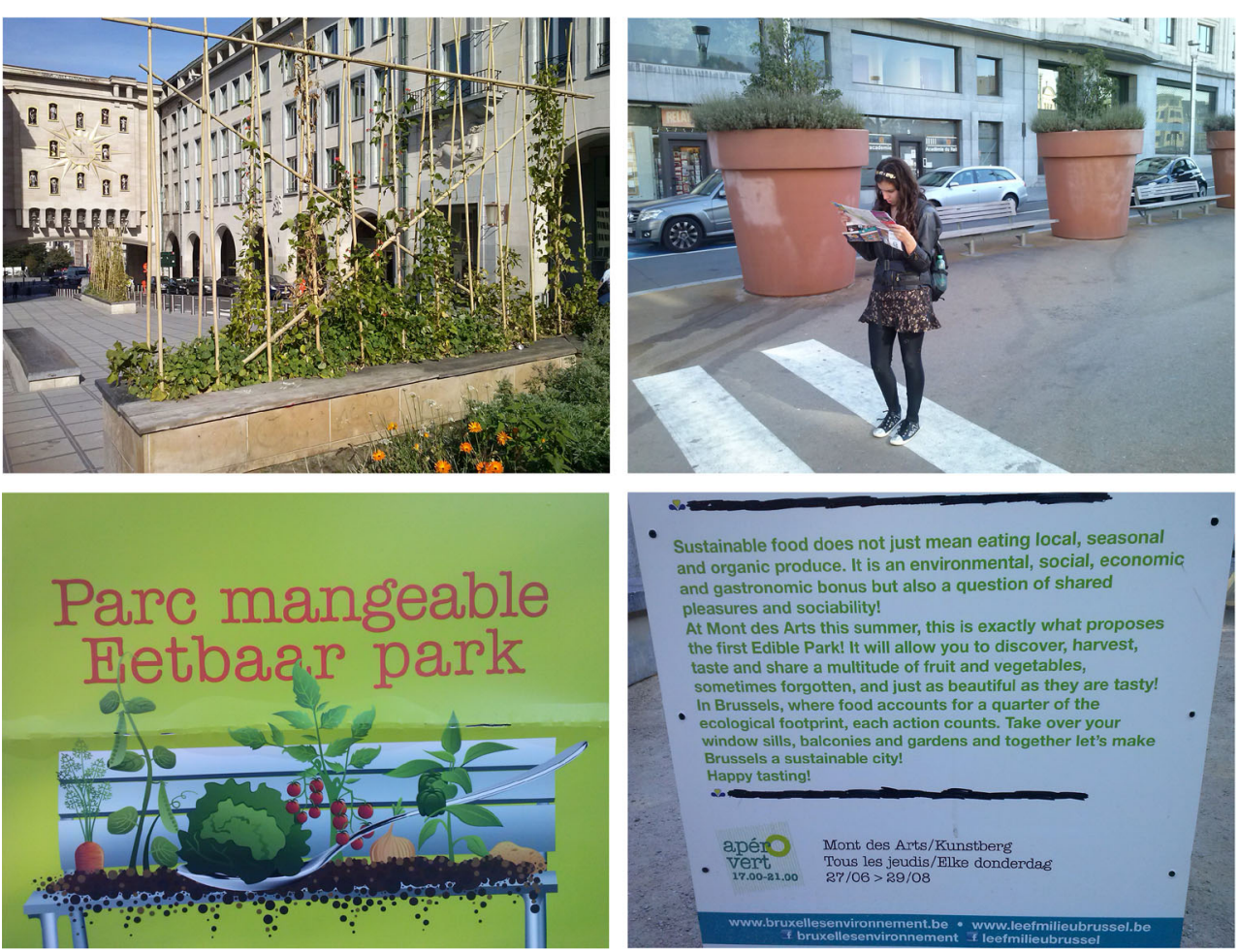

Mediterranean African countries and Latin America, couple efficient use of resources with sustainable costs. Resources include water, recycling waste, and even city compost among others (Orsini et al. 2013; FAO 2014).

\subsection{Organoponics}

An organoponic system, in Spanish "organopónicos," is used in literature for raised beds with a mix of soil and organic matter and is a common cultivation practice in Cuba (Lovell 2010). This cultivation system is mostly found where soil fertility is low and when chemical input is missing. This makes it a suitable system for developing countries and areas without an adequate infrastructure or access to fertilizers and other inputs. Organoponic is especially promoted by government officials in Cuba which is why both the yield and the area of this cultivation method have increased (Orsini et al. 2013). Hamilton et al. (2013) report that the yield of organoponics increased by $17 \%$ between 1994 and 2001. In Cuba, these systems are used for selfconsumption as well as for schools and hospitals. This particular system is extremely sustainable as it operates without fertilizer and is clearly linked to ecologically friendly practices (Orsini et al. 2013). According to Orsini et al. (2013), Cuba is the world leader of this practice. However, it has not yet spread to other countries on this scale. With its environmentally friendly and extremely efficient approach, it is highly suitable for urban horticulture, and its broader adoption should be further considered.

\section{Indoor farming systems}

Due to risks of contamination, some locations in urban areas or even entire cities are rather unsuitable for largescale urban horticulture outdoors. Indoor farming systems use the combined effort of agricultural production and buildings and create an integrated whole within the protected environment of a building (Specht et al. 2013). They can be established as leveled indoor farms in multistorey buildings, or as storefront greenhouses using such technologies. There are many different approaches of integrating indoor farming systems in urban areas. However, there is not a lot of literature providing adequate information about the profitability of urban indoor farming. In the following sections, we have reviewed some indoor farming systems including the integration of greenhouses into urban buildings and the highly discussed Vertical Farming with buildings only built for food production purposes.

\subsection{Building integrated agriculture}

In the literature, different definitions can be found for building integrated agriculture. Caplow (2009) defines it as the 
integration of hydroponic greenhouses into the energy and resource cycle of buildings. Specht et al. (2013) use the term Zero-acreage Farming, also called ZFarming. This term, however, describes all cultivation methods which do not use farmland or open spaces for food production, such as green roofs.

The major aspects that lead to the idea of integrating vegetable production into existing buildings are the saving of resources and higher resource efficiency (Specht et al. 2013). Caplow (2009) sees rooftops of schools, hospitals, hotels, prisons, supermarkets, and shopping malls as ideal settings for building integrated agriculture. These rooftops can be used for the installation of greenhouses. Suitable greenhouses for the positioning on rooftops could be hydroponic systems because of their light weight compared with conventional greenhouses (Caplow 2009).

To achieve a high level of efficiency, it is important to integrate efficient management cycles. Efficiency can be achieved through different means such as energy consumption, nutrient delivery, waste management, and, of course, land use. Nowadays, there is a broad range of highly efficient greenhouse systems which are being used worldwide. By linking these greenhouses to the energy cycles of buildings, emitted energy such as waste heat from air-conditioning systems and refrigerators can be reused and recycled. This is a special advantage in temperate climates as it could secure appropriate heating of the greenhouses during colder months (Caplow 2009). Furthermore, it is possible that the water requirements of the greenhouses can be covered by using recycled or harvested rain water. In terms of nutrition and fertilizing, the use of organic waste in the form of animal waste, plant residues, or waste from food industry or households can be considered (Specht et al. 2013).

Recently, the reduction of energy consumption in greenhouses was implemented by using new covering materials, double and triple thermal screens, climate control strategies, energy-optimized cultivation programs, and greenhouses as solar energy storage. This took place in The Netherlands with the project "de gesloten kas: the closed greenhouse" and in Germany with "ZINEG: the low-energy greenhouse" (Gruda and Tanny 2014). All these systematic tools, together with the use of alternative and renewable energies, without using fossil fuels, can contribute to a reduction of energy consumption by $80-90 \%$ and operate a greenhouse with minimum $\mathrm{CO}_{2-}$ emissions (Gruda and Tanny 2014).

When placing greenhouses on rooftops, it is important that the weight-carrying capacity of the building has been examined. Therefore, it is necessary that greenhouse materials such as roof covering materials are light weight (Specht et al. 2013). Another factor for static reasons is the wind which is especially important with taller buildings. The material used for greenhouses therefore must meet several requirements. They must be energy-saving, suitable for high-quality products, and suitable for static reasons. The great challenge will be finding material that combines all these characteristics.

However, due to the high cost of installation, significant ongoing maintenance, and building weight restrictions, so far, most green roofs are extensive, cultivating drought-tolerant and shallow-rooted plants (Getter and Rowe 2006; Oberndorfer et al. 2007; Mok et al. 2014) whereas implementing intensive horticultural plants on roofs is becoming difficult (Mok et al. 2014).

\subsection{Vertical farming}

Probably, the most complex and futuristic concept of urban agriculture is Vertical Farming. The main advocate for this production type is Dickson Despommiers, a retired Professor from Columbia University in New York. The vertical production of crops would allow more cultivation area on a relatively small base area and could therefore reduce the need for large expanses of arable land. Major advantages are the close proximity of a large-scale crop production to the consumers and the controlled environment throughout the building allowing higher yields (Despommiers 2013).

A specific concept of Vertical Farming, envisaged to produce the staple crop rice, is the so-called Skyfarming. Germer et al. (2011) discuss the possibilities and constraints that arise with farming rice crops vertically. For minimum weight, and therefore lower statistical requirements, an aeroponic system is suggested which would supply the rice roots with a mist enriched with nutrients (Germer et al. 2011). According to Mok et al. (2014), the article by Germer et al. (2011) is the only one of its kind rationalizing the technical constraints and advantages of Vertical Farming concepts and putting Despommiers (2010) ideas to the test. However, it is also the only article and concept focusing on vertical rice production.

We could not agree more with Mok et al. (2014) that this topic needs more economic assessment. We find, however, that the literature on urban agriculture neglects already existing and operating Asian indoor farms. In these so-called plant factories, vegetables are cultivated indoors under fully controlled conditions. Computers and sensors control and measure the main environmental factors that affect vegetable growth, such as lighting, carbon dioxide concentration, relative humidity, and plant surface temperature (Chang et al. 2011). Despommiers (2013) reports of many economically viable enterprises situated in peri-domestic areas in Japan, using both natural sunlight and artificial lighting. As land costs are significantly higher in cities, their economic viability for urban areas has to be reassessed taking the higher capital expenditures into consideration.

As the production systems are not directly dependent on soil and climate factors, cultivation can take place all year round independent of weather extremes. The systems run without soil so are not involved in agricultural runoff, one of 
the most important issues at present. Furthermore, a better control of pesticides and fertilizers is possible. One of the greatest advantages is that Vertical Farming is not reliant on favorable climatic conditions. In this way, even cities or sites with contaminated soil or severe weather extremes could grow healthy food sustainably and independently from others (Despommiers 2013).

\subsection{New technologies for indoor farming}

Cultivating vegetables vertically has a variety of advantages. However, the issue of a satisfactory light source poses a great challenge to both horticulturists and researchers. In the case of vertical farming, plants are isolated in a building in which the amount of sunlight is not at the same level as in a greenhouse. As light is essential for the plants' photosynthesis, it is necessary to install light sources to ensure sufficient yields and high-quality products. This leads to the necessity of providing the plants with highly efficient artificial light sources.

Nowadays, artificial lighting is still used in horticultural greenhouse production and laboratories in order to mitigate the adverse influence of low and short radiation levels, creating optimal growing conditions for protected crops. The development of light-emitting diode (LED) lamps offers the use of plant-related radiant energy due to optimization of the plant management processes. This is very important for plant growth, plant development, and product quality (Gruda and Tanny 2014). LED lamps have several unique advantages over existing horticultural lighting, such as being small in size and having increased longevity and low heat emission even at very high light intensity levels. In addition, LED lamps have the ability to control spectral composition, giving the opportunity to select the most favorable light spectrum for photosynthesis (Fig. 5) (Morrow 2008; Paradiso et al. 2011; Gruda and Tanny 2014).

According to Morrow (2008), the LED array provides three times more light output for the same wattage of input power on an equivalent area basis and can be easily integrated into digital control systems. Some recent literature has examined the influence of the light spectrum. The increase of blue light (Hogewoning et al. 2010) led to an increase of greenhouse cucumbers biomass: Additionally raising lettuce seedlings treated with blue light also promoted the growth of plants after transplanting in terms of high shoot and root biomasses, high content of photosynthetic pigments, and high antioxidant activities in the lettuce seedlings before transplanting (Johkan et al. 2010). Gruda and Tanny (2014) state that plant-specific choice of light intensity and spectrum with a combination of far red and blue light rate using LED could contribute to a reduction of fertilizer and chemical use, due to an aimed shortening of the vegetation period and improvement in plant morphology. However, although LED has little energy

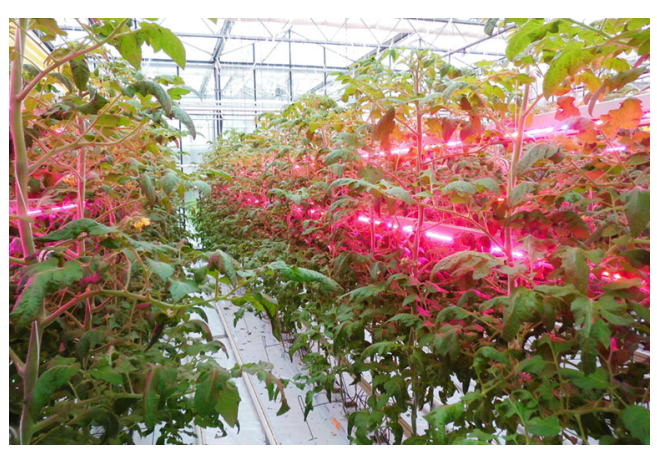

Fig. 5 The development of light-emitting diode (LED) lamps offers the use of plant-related radiant energy due to optimization of plant management processes. The advantages of using these lamps over existing horticultural lighting are their small size and longevity. LED lamps have the ability to control spectral composition, i.e., to select the most favorable light spectrum for photosynthesis. Since they emit low heat even at very high light intensity levels, they are also used for "interlighting," i.e., the lighting between rows, as shown in this figure. Here they are used for greenhouse tomatoes at a research station in Germany. This way, light reaches even very-low-hanging leafs and improves yield and product quality (Figure: Gruda, 2013, private collection)

consumption and produce very little heat, the energy costs are still high.

Despite the resource efficiency of indoor farming systems, they are still very expensive.

\section{Features of urban horticulture}

\subsection{Food security}

Urban food security depends on different factors: availability of food, access to food, and quality of food. With urban farming, all of these factors can be improved. All cultivation methods described can have a significant contribution to communities and their families' food security. In respect to production for self-consumption, regardless of the income level, food and nutrition security can be improved by growing food in a home or community garden (Kortright and Wakefield 2011; Lovell 2010). According to Orsini et al. (2013), urban horticulture already has a significant contribution to nutrition and food security in developing countries. Especially in developing countries, a constant migration from rural to urban areas is projected to take place. This is why the significance of urban horticulture is likely to increase further in the future.

By implementing urban horticulture in cities of the future, a greater scale of food security could be achieved. However, to gain global food security, attention has to be paid to both urban and rural agriculture. With urban horticulture alone, global food security cannot be achieved. However, urban food production on a large scale could take some pressure from rural agriculture (Specht et al. 2013). Urban horticulture could also help reach a certain balance between food availability in rural and urban areas. But even with a highly developed 
worldwide urban horticulture, rural agriculture will keep its significance concerning global food security (Dubbeling et al. 2010)

Cuba is a very special example when it comes to the scale of urban farming. After the break down of the Soviet Union, Cuba had lost their major trade partner. As a consequence, urban agriculture evolved as the solution for self-sufficiency and food security (Fig. 6). Because of the lack of inputs like fertilizers, pesticides, or fuel for food transportation into the city, labor-intensive, chemical-free, and urban became the main characteristics of Cuban food production. Today, more than 35,000 ha in the urban and peri-urban areas of Havana, the capital of Cuba, are used for food production. This makes Cuba the leading country in urban agriculture globally (Hamilton et al. 2013; Lovell 2010).

\subsection{Social and education}

Apart from the significant contribution urban agriculture can have on food security, the impacts on social inclusion of minority groups or in education are of a similar scope.

In developing countries, employment opportunities outside the agricultural sector are often rare. Through the increasing demand in cities for food, it is projected that urban agriculture will create more jobs in the future (de Bon et al. 2010). Urban farming also favors both social inclusion and reduction of gender inequalities as $65 \%$ of urban farmers are women (Orsini et al. 2013). Because of the close proximity to the home, gardening can be much better combined with child care which is still seen as a woman's duty in many countries (Dubbeling et al. 2010). Therefore, getting involved in home gardening empowers women being more independent (Galhena et al. 2013; Lovell 2010).

While many cities worldwide experience an immense growth, rather the opposite can be found in crisis-ridden cities such as Cleveland, Ohio, USA (Grewal and Grewal 2012).

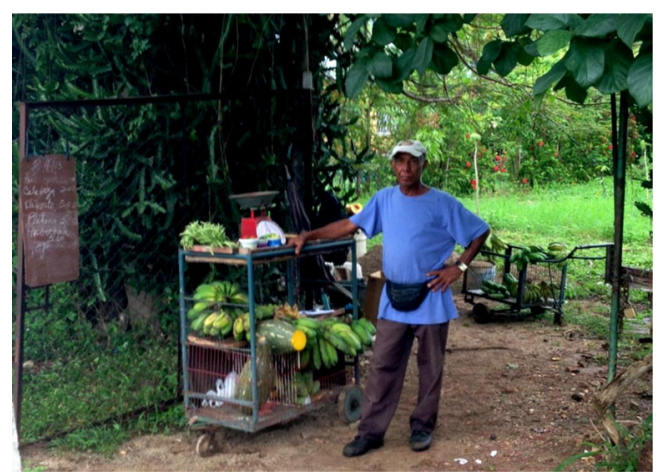

Fig. 6 From 1997 to 2003, Havana's urban agriculture experienced an annual average growth of $38 \%$. This was made possible through different networks and state services which provided technical assistance as well as equipment such as seeds and fertilizer. In this image, an urban farmer is selling his own produce in front of an urban garden in Havana, Cuba (Figure: Eigenbrod, 2013, private collection)
Economic crises and foreclosures of homes result in an ongoing rise of vacant land. Creating community gardens on this vacant land would empower local communities to be more self-reliant, increases food and nutrition security and has the potential to reduce crime rates (Metcalf and Widener 2011).

Several sources (Mok et al. 2014; Galhena et al. 2013; Lovell 2010) report that especially low-income families which belong to a minority group struggle to access healthy and affordable food. By engaging these people in urban agriculture, the communities can be strengthened, and their food security significantly increased. In Cologne, Germany, intercultural community gardens were established to give migrants the chance for better integration and also for the opportunity to grow crops from their respective homeland which are not available in German stores (Dubbeling et al. 2010).

Many authors report positive effects of school gardens and urban agriculture in education (Dubbeling et al. 2010; Specht et al. 2013; Lovell 2010). The educational function of urban agriculture can reach from activities offered in community gardens to an implementation of urban agriculture in school curriculums. The Manhattans School for Children in Manhattan, United States of America, teaches children about sustainably cultivating plants in urban hydroponic greenhouse on a rooftop. To increase the awareness for healthy food and to teach science skills in a hands-on environment, many Chicago and Milwaukee Public Schools have urban agriculture integrated in their curriculums. During the class, students are responsible to feed the fish, test the water quality, and build their own miniature systems (Fig. 7). The school children also learn about resource management, sustainability, and biodiversity (Specht et al. 2013). In developing countries, school gardens can significantly increase the food and nutrition security of the school children and their families (Dubbeling et al. 2010). Mok et al. (2014) state that school gardens usually have lower outputs as their primary purpose is education. However, school gardens could also be used as a research project for teachers and therefore help increase the yield and the sustainability of the respective production system used.

Surely, horticultural gardens are getting more and more important for educational purposes in city parks. Figure 8a$\mathrm{d}$ illustrate these efforts in two different cities in Australia and Europe. Taking into account peri-urban agriculture, e.g., in Australia (Mok et al. 2014), or greenbelts in Europe, will change this picture drastically and make an urban agriculture contribution quite significant.

Integrating urban horticulture into educational and social programs improves nutrition and food security.

\subsection{Policy}

Since early 2008 when oil and food prices increased sharply, sales of vegetable seeds have increased by $20 \%$ (McClintock 2010). The increased interest in urban agriculture is a typical 

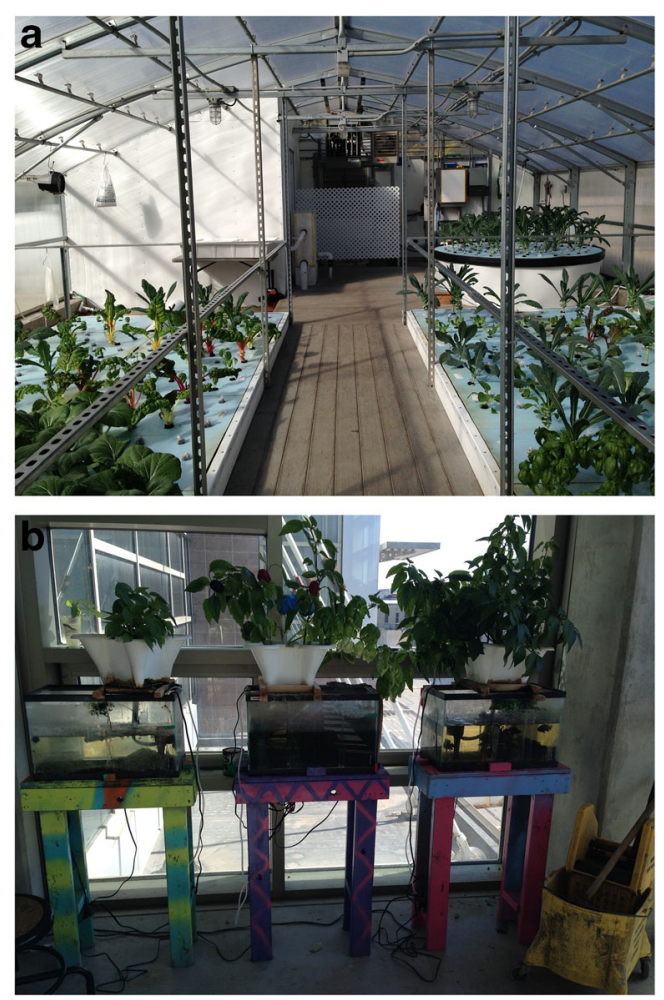

Fig. 7 a Shows an aquaponic greenhouse at a Milwaukee Public School. Students help the teacher plant seedlings and harvest. They also monitor the water quality of the fish tanks. The produced basil, chard, and perch are sold to local restaurants. b Shows three miniature aquaponic systems built and designed by students. These miniature systems are used for ornamental fish or young tilapia. Students can choose the type of plants and fish and maintain the system throughout the school year (Figures: Eigenbrod, 2014, private collection)

reaction to a national crisis as already experienced during World Wars I and II with the War Gardens and Victory Gardens (Mok et al. 2014). And now again, for the first time in 60 years, Michelle Obama, the First Lady of the USA, planted a vegetable garden at the White House (McClintock 2010).

With this great increase in urban agriculture, it is important that urban agriculture is embraced on a policy level. Therefore, more institutions and organizations which are backed by the government must be established in order to secure growth and promotion of urban farming projects. This is especially important to prevent an uncontrolled spread of urban agriculture across a city which could mean an unbalance within the urban infrastructure and also propagation of urban horticulture in unsuitable areas. Especially in developing countries, urban agriculture would need more support and promotion from governments because of its positive impact on employment opportunities and livelihoods. Although it is often tolerated, it is not particularly encouraged in many countries. This, however, is reported to be changing slowly (de Bon et al. 2010).

Having a secured and sustainable food supply in cities is not only dependent on whether there are enough food products available in cities, but also on sufficient access to resources (de Zeeuw et al. 2000). Lovell (2010) reports that people from marginalized groups often lack access to land. However, it is especially these groups who need healthy and cheap food the most. By establishing more community gardens and providing more public green spaces, urban horticulture would be more accessible to all people and especially to those who need it the most (Lovell 2010). It is commonly assumed that the yields from urban farmers are low. This occurs to a great extent because of poor-quality inputs, lowtechnology farm practices, and high losses from a variety of sources (Nugent 2000). The yields strongly depend on the welfare of the households practicing urban horticulture (Bakker et al. 2000). Through a greater availability of high quality inputs and advisory services, underprivileged families could achieve higher yields and thus a higher level of selfsupply (Nugent 2000).

Taylor and Lovell $(2012,2014)$ report that governments and actors in urban agriculture tend to lay their focus on community gardens and green open spaces. The significance of urban home gardening is often ignored. Considering the great significance of home gardening for food security, it is important that home gardening gets greater attention from governments and municipalities.

The integration of urban agriculture into urban planning processes is the key to a sustainable implementation. As this is not yet standard, governments and municipalities should get involved in planning and establishing urban agriculture (Drescher et al. 2005). Therefore, collaboration with different stakeholders such as growers, residents, architects, and many others is important (Dubbeling et al. 2010). If not implemented correctly and with caution, urban agriculture can pose a threat to both humans and the environment. To avoid pollution of groundwater and crop contamination, locations within the city should be chosen carefully. In order to prevent urban agriculture in risky areas, governments and municipalities could make certain vacant spaces available. By mapping vacant spaces and the amount of land used for urban agriculture through Google Earth images as done in New York and Chicago (Kremer et al. 2013; Taylor and Lovell 2012), all stakeholders involved can get a better overview of the current state of urban agriculture in the area and the potential. However, there are many municipalities which have incorporated urban agriculture into the municipal food system (Hamilton et al. 2013; Lovell 2010; Mok et al. 2014; Bohn and Viljoen 2011).

Integrating urban horticulture into urban planning processes and supporting it through policies makes it more sustainable.

\subsection{Environmental factors and climate change}

As Godfray et al. (2010) report, there is potential in increasing the average global yields by closing or minimizing the yield gap. This would have significant impact on the increase of 
Fig. 8 a The city of Brisbane, Australia, recently hosted the latest International Horticultural Congress, back in August 2014. At the Roma-Street-Park, the third largest urban park worldwide, a very diverse horticultural garden was placed. Whereas in the foreground there are some vegetables, different pot-herbs can be seen in the background. Herbs and vegetables are placed in the South Bank, near the Exhibition Center of Brisbane as well. (b, c, d) Another way was chosen by landscape architects and horticulturist in a touristic town in France. In the park of Pornichet, kitchen herbs were planted beside ornamental plants. The visitors were asked by columns to decide the right name of kitchen herbs. By opening the windows, visitors were then informed about the right name of this herb, e.g., Melissa officinalis (Figures: Gruda, 2014, private collection)
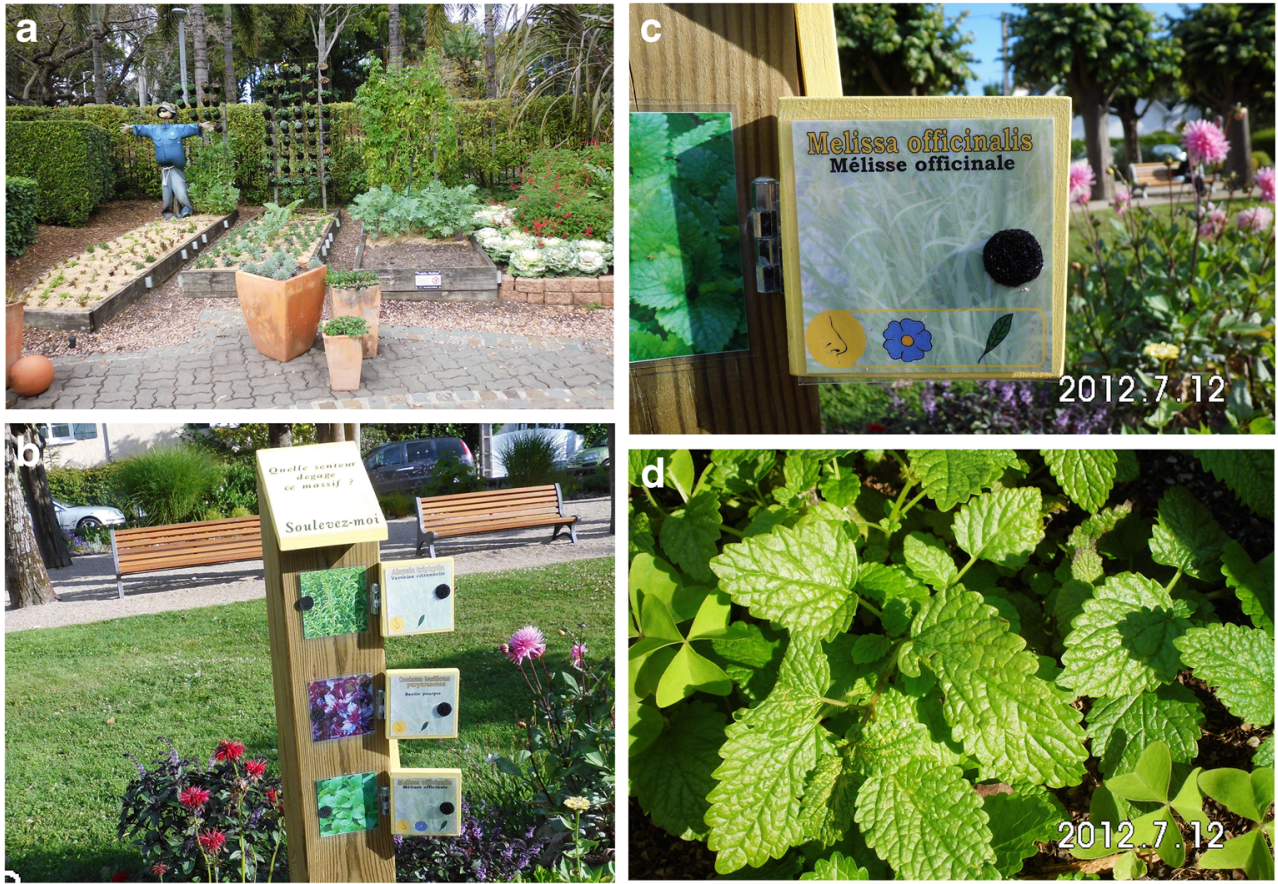

global food production and therefore on global food security. Major reasons for harvest or yield losses are pests, diseases, and extreme weather conditions such as droughts or storms. Due to climate change, weather extremes are projected to deteriorate in the coming decades. Vermeulen et al. (2012) predict that a rise of $2{ }^{\circ} \mathrm{C}$ of the global mean temperature by 2100 will already destabilize agricultural production systems.

While cultivating vegetables outdoors is cheaper concerning energy and technology, some areas are not particularly suitable for food production. A recent study in Berlin has shown that vegetables grown in inner city areas can accumulate high amounts of trace metals (Säumel et al. 2012). The respective accumulation depended on the type of vegetable. Whereas in leafy vegetables a high amount of trace metals has been detected, root vegetables only showed a medium amount. Therefore, it cannot be said that vegetables grown in inner city areas automatically pose a risk to human health. For instance, an adult consuming an average of $100 \mathrm{~g}$ of carrots, tomatoes, kohlrabi, chard, and potatoes respectively a day would only take up $3 \%, 17 \%, 5 \%$, and $15 \%$ of the accepted daily amount of $\mathrm{Zn}, \mathrm{Pb}, \mathrm{Cu}$, and $\mathrm{Cd}$. However, these amounts of trace metals can be much higher when the vegetables are grown on sites with extremely high pollution (Säumel et al. 2012). In order to decrease the risk of heavy metal uptake from vegetables, cultivation sites have to be chosen carefully. Säumel et al. (2012) reports that barriers built between cultivation areas and roads can reduce risks of contamination significantly. In areas where contaminations are more likely, Lovell (2010) suggests to use these areas for non-edible crops such as Christmas trees and crops which do not accumulate metals in their edible parts. At locations with polluted soil, a contamination can be prevented by cultivating plants in raised beds or containers such as boxes and rice sacks.

On one hand, urban environments are often highly polluted by industry, domestic activities, and transport (Hamilton et al. 2013). At the same time, agriculture is known to pollute the environment through the use of pesticides, and chemical and organic fertilizers (Mok et al. 2014). In order to avoid pollution by urban farming, organic agriculture has been promoted in several cities in Germany, The Netherlands, and Slovenia. Organic agriculture is also a tool to maintain and enhance biodiversity in urban areas (de Bon et al. 2010). A cultivation of plants and vegetables in containers, hydroponic, and aquaponic systems or even in indoor farms is therefore not only positive in terms of crop contamination; it also prevents fertilizers and pesticides leaking into the environment.

Urban horticulture plays a crucial role in making cities greener and creating a more natural environment. Through recycling, the re-use of organic wastes, and the reduction in energy consumption, it lessens the cities' ecological footprints (de Zeeuw et al. 2000; Bohn and Viljoen 2011). In addition, food produced in urban areas usually does not have as many "food miles" as rurally cultivated vegetables. The average 
delivery distance of food is $1,640 \mathrm{~km}$; including the total supply chain, the average distance traveled is $7,564 \mathrm{~km}$ (Specht et al. 2013). With urban food production, the logistical and storage costs would drop and, additionally, the environmental pollution through $\mathrm{CO}_{2}$ emissions would be reduced significantly. The vegetables would be fresher and have a prolonged shelf life because they could reach the supermarket up to hours after harvesting. In temperate climates, cities usually can offer more favorable conditions than the rural surroundings because they are typically about $2^{\circ}$ to $3{ }^{\circ} \mathrm{C}$ warmer (Shackleton et al. 2009). This prolongs the growing season and therefore increases the total output and makes an integration of food production in urban areas more attractive.

Agriculture is one of the major contributors to climate change. It is assumed that $20-30 \%$ of the global greenhouse gas emissions are caused by food production (Kulak et al. 2013). In the case of indoor farming systems, urban horticulture cannot only prevent food production from being influenced by pollution or weather extremes due to climate change, but it also has potential to serve to mitigate climate change as these systems work energy efficiently and therefore have less carbon emissions (Specht et al. 2013). It could only have a greater impact on the mitigation of climate change if the systems were adopted on a larger scale. This, however, is not very likely in the coming decades because of high costs and policy restraints. However, it can be said that urban agriculture in general can mitigate climate change in terms of carbon emissions caused by food miles, storage, cooling, and packaging (Specht et al. 2013).

Evaluating locations for cultivation and choosing suitable vegetable species reduces the risk of contamination.

\subsection{Self-sufficiency of cities}

An important debate within the urban agriculture movement is what level of self-sufficiency cities can realistically obtain (Mok et al. 2014). According to the authors, in the case of urban agriculture, self-reliance means the ability to produce enough food for people living in an urban area without having to rely on external resources. Many cities already have the requirement for self-sufficiency in vegetables. That shows that the challenge is whether cities are able to transform into selfregulating and sustainable systems. Deelstra and Girardet (2000) even go so far as to claim that there can be no sustainable world without sustainable cities. However, Grewal and Grewal (2012) indicate that, in today's globalized world, towns or cities should not be isolated in terms of production but just aim to be as self-reliant as possible in terms of basic necessities such as food.

As Mok et al. (2014) report, little research has been done on self-sufficiency in food in cities. Grewal and Grewal (2012) have calculated that Cleveland, Ohio, United States of America, with its approximate 400,000 citizens has the potential to achieve $100 \%$ autonomy with regards to meeting their fresh vegetable requirements. Therefore, hydroponic greenhouses would have to be established on every available rooftop and vacant space. The space required for the same yield with conventional cultivation would be 14 times greater.

For the city of Frankfurt (Germany) with a population of 690,000 inhabitants, a plant factory with 25 levels with a ground area of $216 \mathrm{~m}^{2}$ would be needed to supply its citizens with a daily amount of $400 \mathrm{~g}$ of vegetables, which is the daily consumption recommendation of the German Nutrition Society (Oberritter et al. 2013).

These numbers suggest that self-sufficiency could potentially be achieved. However, it has to be considered that both of these scenarios do not include other essential parts of the diet such as protein and grain which would require much more space as indicated earlier (Mok et al. 2014). That is why realistically self-sufficiency of cities could only be achieved in terms of vegetables. Also, for the example of Cleveland, it would need the local government's support to approve setting up greenhouses on so many rooftops which would also translate to high investment costs. The example of Frankfurt is still futuristic and only shows a theoretical potential of selfsufficiency as the viability of indoor farms in cities still has to be analyzed.

Although vegetable self-sufficiency of cities can potentially be achieved, it might not be sustainable or desirable.

\section{Discussion}

Throughout this paper, we identified urban horticulture as having great potential, but also many weaknesses and constraints. Despite the various constraints, many authors confirm the significance of urban horticulture for food and nutrition security. In order to better implement urban agriculture, it is important to consider all the potentials and the limitations. We identified the following three points which are controversially discussed in the literature and which therefore need further attention.

1. Urban food production reduces so-called food miles significantly. However, local food does not automatically say that the food produced is environmentally sustainable. Schnell (2013) sees the local food movement rather critical and rational. He argues that "locavores" often neglect other important factors concerning sustainability such as seasonality. Cultivating vegetables in urban areas might sound sustainable from a food miles point of view. However, if the vegetables species are out of season, their production might need more energy than shipping produce from a country with more favorable growing conditions (Schnell 2013; Hamilton et al. 2013; Mok et al. 
2014). Hamilton et al. (2013) and Mok et al. (2014) further argue that the natural smaller scale of urban agriculture needs more inputs as well as energy in comparison to conventional agriculture. They further state that shifting the production to areas with less favorable growing conditions could increase the amount of fertilizer needed. However, this does not take into account the potential of highly efficient production systems working on a larger scale than private persons and community gardens. Besides, the significant reduction of energy costs for cooling, packaging, and storage also have to be considered in this calculation (Specht et al. 2013).

2. Mok et al. (2014) and Hamilton et al. (2013) argue that urban agriculture might increase the net carbon emissions by producing on a smaller scale and under less favorable conditions, thereby requiring more energy and fertilizer. However, this argument does not reflect the positive impacts urban agriculture can have on communities and their livelihoods, nor does it address the environmental impact on cities. If growers focused on cultivating more local and therefore climatic adapted crops which are in season at the time, the concern referring to the less favorable conditions would lapse.

3. In terms of food security and resilience, it might be vital in the future to have more urban vegetable production working on a larger scale. Therefore, it is worthwhile to also consider yet futuristic concepts of urban horticulture which could work on a larger scale without being influenced by unfavorable weather conditions or likely contaminations of the produce. However, food security is especially a problem in developing countries. These countries usually lack of inputs and equipment needed for more modern and technological systems. For instance, hydroponic and aquaponic systems require large quantities of water and high maintenance and knowledge to achieve high yields. Because of the high running costs and high-quality inputs needed, these systems are not particularly suitable for developing countries. The highly discussed Vertical Farming as an indoor farming approach, especially, is far from being feasible and sustainable, even in developed countries (Mok et al. 2014).

\section{Conclusion}

All over the world, urban horticulture already contributes to food and nutrition security, and its importance is likely to increase further because of the steadily growing population and urbanization. With our analysis, we found that, although urban horticulture has its constraints, we think positive impacts predominate. By implementing urban horticulture correctly and with caution, most of the risks and constraints can be eliminated. In the following, we identified four points that we found important to consider:

1. When considering urban agriculture, it is important to bear in mind that urban agriculture should only be seen as complementary to rural agriculture. Also, urban growers producing on a smaller scale should not be seen as a concern because of the lower productivity, but rather as a welcoming factor contributing to cities' sustainability and food security.

2. Urban horticulture is not suitable for every area due to risks of contamination. Instead of banning urban horticulture or restricting it, it should rather be seen as a challenge to adjust the cultivation to the given circumstances and to take precautionary measures so that urban horticulture is possible and the food products are safe.

3. Furthermore, there are already technologies which save huge amounts of energy in greenhouses and even operate with artificial light sources. Considering these technical possibilities could mean great savings in costs for future vertical farms. From our analysis, today's actors in vertical farming come from different professions. The efforts are adequate, but sometimes very important factors such as growers and "the horticulturists" with their "horticultural knowledge" are completely ignored. For instance, the recent discussions on Vertical Farming focused on various futuristic designs by architects instead of actual crop production technology. In order to realize the concept of vertical farms with vegetables, it is essential that the achievements made in greenhouse cultivation and indoor cultivation in the field of horticulture are considered for future vertical farming projects. It is therefore important that architects, city planners, biologists, economists, engineers, and environmental scientists work closely with horticulturists in the future. In this way, the projects are more likely to be realizable, coherent, and successful.

4. We reviewed different types of urban horticulture in this paper. These cultivation systems all have their respective advantages and disadvantages. However, for different areas in the world, with different conditions and requirements, there are different cultivation methods. Therefore, it cannot be said that one method is better than the other as it has to be seen in the context of the respective environment. It can be assumed that modern and highly efficient approaches are more likely to emerge in developed countries whereas developing countries will have simpler systems dominating which do not need as much inputs or maintenance.

With our analysis, we found that urban horticulture has to be seen in the respective context. Urban horticulture has various constraints, but also many advantages. Because of different circumstances and conditions all over the world, it 
is important to adapt production systems to the respective location. The motto for future food production should not be "local at any price," but "as sustainable as possible." This prevents food being produced under high costs and energy consumption. However, with today's technology and further research, it might be possible in the future to produce vegetables under controlled conditions with low energy costs and more sustainability.

The increasing pollution of our planet and the predicted weather extremes may make it necessary to put more trust into controlled environment agriculture in the future. Energy efficiency of cultivation facilities is a very important and current issue, and vegetable production will probably become more efficient in the coming years. For establishing highly efficient greenhouses or indoor farms, scientists with different expertise will be necessary. Therefore, it is important to make the protected production facilities of future cities both sustainable and suitable for high-quality and high-yielding vegetables. In this context, we can say, better with us, horticulturists, than without us.

Acknowledgments Special thanks to Nerys Law and Mandy Sawier as native speakers, for the critical reading of the manuscript.

\section{References}

Aubry C, Ramamonjisoa J, Dabat MH, Rakotoarisoa J, Rakotondraibe J, Rabeharisoa L (2012) Urban agriculture and land use in cities: an approach with the multi-functionality and sustainability concepts in the case of Antananarivo (Madagascar). Land Use Policy 29:429439. doi:10.1016/j.landusepol.2011.08.009

Bakker N, Dubbeling M, Gündel S, Sabel-Koschella U, de Zeeuw H (2000) Growing cities, growing food. Dtsch Stift int Entw, Feldafing, p 531

Bohn K, Viljoen A (2011) The edible city: envisioning the continuous productive urban landscape. Field J 4(1):149-161

Caplow T (2009) Building integrated agriculture: philosophy and practice. In: Urban futures 2030: Urban development and urban lifestyles of the future, ed. Heinrich Böll Foundation, 54-58. Berlin, Germany: Heinrich-Böll-Stiftung

Chang YW, Lin TS, Wang JC, Chou JJ, Liao KC, Jiang JA (2011) The effect of temperature distribution on the vertical cultivation in plant factories with a WSN-based environmental monitoring system. Adv Biomed Eng 3-5:234-240

De Bon H, Parrot L, Moustier P (2010) Sustainable urban agriculture in developing countries. A review. Agron Sustain Dev 30:21-32. doi: 10.1051/agro:2008062

de Neergard A, Drescher AW, Kouamé C (2009) Urban and peri-urban agriculture in African cities. In: Pasquini CM, Drescher MW, Shackleton AW (eds) African indigenous vegetables in urban agriculture. Earthscan, London, pp 35-58

de Zeeuw H, Guendel S, Waibel H (2000) The integration of agriculture in urban policies. In: Bakker N, Dubbeling M, Gündel S, SabelKoschella U, de Zeeuw H (eds) Growing cities. Growing Food. Dtsch Stift int Entw, Feldafing, pp 161-180

Deelstra T, Girardet H (2000) Urban agriculture and sustainable cities. In: Bakker N, Dubbeling M, Gündel S, Sabel-Koschella U, de Zeeuw H (eds) Growing cities. Growing Food. Dtsch Stift int Entw, Feldafing, pp 43-66

Despommiers D (2010) The vertical farm: feeding the world in the 21st century. St Martin's Press, New York

Despommiers D (2013) Farming up the city: the rise of urban vertical farms. Trends Biotechnol 7:388-389. doi:10.1016/j.tibtech.2013.03.008

Drescher AW, Jacobi P, Amend J (2005) Urban food security - urban agriculture, a response to crisis? http://www.ruaf.org/node/106. Accessed 5 May 2013

Dubbeling M, de Zeeuw H, van Veenhuizen R (2010) Cities, poverty and food-multi-stakeholder policy and planning in urban agriculture. RUAF Foundation, Rugby, p 173

FAO (1996) The state of food and agriculture. Food and Agriculture Organization, Rome

FAO (2014) Growing greener cities in Latin America and the Caribbean. An FAO report on urban and peri-urban agriculture in the region. Rome 2014. ISBN 978-92-5-108250-8

FAOSTAT (2013) FAO statistical yearbook 2013. ISBN 978-92-5107396-4 http://www.fao.org/docrep/018/i3107e/i3107e.pdf. Accessed 13 September 2014

Foley JA, Ramankutty N, Brauman KA, Cassidy ES, Gerber JS, Johnston M, Mueller ND, O’Connell C, Ray DK, West PC, Balzer C, Bennett EM, Carpenter SR, Hill J, Monfreda C, Polasky S, Rockstrom J, Sheehan J, Siebert S, Tilman D, Zaks DPM (2011) Solutions for a cultivated planet. Nature 478:337-342

Galhena DH, Freed R, Maredia KM (2013) Home gardens: a promising approach to enhance household food security and wellbeing. Agric Food Secur 2:8. doi:10.1186/2048-7010-2-8

Germer J, Sauerborn J, Asch F, de Boer J, Schreiber J, Weber G, Müller J (2011) Skyfarming an ecological innovation to enhance global food security. J Verbr Lebensm 6:237-251. doi:10.1007/s00003-0110691-6

Getter KL, Rowe DB (2006) The role of extensive green roofs in sustainable development. Hortscience 41:1276-1285

Godfray HCJ, Beddington JR, Crute IR, Haddad L, Lawrence D, Muir JF, Pretty J, Robinson S, Thomas SM, Toulmin C (2010) Food Security: the challenge of feeding 9 billion people. Science 327:812-818. doi: 10.1126/science. 1185383

Grewal SS, Grewal PS (2012) Can cities become self-reliant in food? Cities 29:1-11. doi:10.1016/j.cities.2011.06.003

Gruda N (2005) Impact of environmental factors on product quality of greenhouse vegetables for fresh consumption. Crit Rev Plant Sci 24(3):227-247. doi:10.1080/07352680591008628

Gruda N (2009) Do soilless culture systems have an influence on product quality of vegetables? J Appl Bot Food Qual 82:141-147

Gruda N, Tanny J (2014) Protected crops. In: Dixon GR, Aldous DE (eds) Horticulture-plants for people and places. Book 1 . Production Horticulture Springer Science+Business Media Verlag, Heidelberg / New York, 327-405. doi:10.1007/978-94017-8578-5 10

Gruda N, Prasad M, and Maher MJ (2007) Soil-less culture: In: Lal R (Eds) Encyclopedia of soil sciences (Second Edition). Taylor \& Francis. doi:10.1081/E-ESS-120028194

Hamilton AJ, Burry K, Mok H-F, Barker F, Grove JR, Williamson VG (2013) Give peas a chance? Urban agriculture in developing countries. A review. Agron Sustain Dev 34:45-73. doi:10.1007/s13593013-0155-8

Hogewoning SW, Trouwborst G, Maljaars H, Poorter H, van Ieperen W, Harbinson J (2010) Blue light dose responses of leaf photosynthesis, morphology, and chemical composition of Cucumis sativus grown under different combinations of red and blue light. J Exp Bot 61(11): 3107-3117. doi:10.1093/jxb/erq132

Johkan M, Shoji K, Goto F, Hashida S, Yoshihara T (2010) Blue lightemitting diode light irradiation of seedlings improves seedling quality and growth after transplanting in red leaf lettuce. HortSci 45(12): 1809-1814 
Jones JB Jr (1982) Hydroponics: its history and use in plant nutrition studies. J Plant Nutr 5:1003-1030. doi:10.1080/ 01904168209363035

Kortright R, Wakefield S (2011) Edible backyards: a qualitative study of household food growing and its contributions to food security. Agric Hum Values 28:39-53. doi:10.1007/s10460-009-9254-1

Kremer P, Hamstead ZA, McPhearson T (2013) A social-ecological assessment of vacant lots in New York City. Landsc Urban Plan 120:218-233. doi:10.1016/j.landurbplan.2013.05.003

Kulak M, Graves A, Chatterton J (2013) Reducing greenhouse gas emissions with urban agriculture: a LifeCycle assessment perspective. Landsc Urban Plan 111:68-78. doi:10.1016/j.landurbplan. 2012.11.007

Lovell ST (2010) Multifunctional urban agriculture for Sustainable land use planning in the United States. Sustainability 2:2499-2522. doi: $10.3390 /$ su2082499

Mbaye A, Moustier P (2000) Market-oriented urban agricultural production in Dakar. In: Bakker N, Dubbeling M, Gündel S, SabelKoschella U, de Zeeuw H (eds) Growing cities. Growing Food. Dtsch Stift int Entw, Feldafing, pp 235-256

McClintock N (2010) Why farm the city? Theorizing urban agriculture through a lens of metabolic rift. Cambridge J Reg Econ Soc 1-17. doi:10.1093/cjres/rsq005

Metcalf SS, Widener MJ (2011) Growing Buffalo's capacity for local food: a systems framework for sustainable agriculture. Appl Geogr 31:1242-1251. doi:10.1016/j.apgeog.2011.01.008

Mok H-F, Williamson VG, Grove JR, Burry K, Barker SF, Hamilton AJ (2014) Strawberry fields forever? Urban agriculture in developed countries: a review. Agron Sustain Dev 34:21-43. doi:10.1007/ s13593-013-0156-7

Morrow RC (2008) LED lighting in horticulture. HortSci 43(7):1947_ 1950

Mougeot LJA (2000) Urban agriculture: definition, presence, potentials and risks. In: Bakker N, Dubbeling M, Gündel S, Sabel-Koschella U, de Zeeuw H (eds) Growing cities. Growing Food. Dtsch Stift int Entw, Feldafing, pp 1-41

Nugent R (2000) The impact of urban agriculture on the household and local economies. In: Bakker N, Dubbeling M, Gündel S, SabelKoschella U, de Zeeuw H (eds) Growing cities. Growing Food. Dtsch Stift int Entw, Feldafing, pp 67-97

Oberndorfer E, Lundholm J, Bass B, Coffman RR, Doshi H, Dunnett N, Gaffin S, Kohler M, Liu KKY, Rowe B (2007) Green roofs as urban ecosystems: ecological structures, functions, and services. Bioscience 57:823-833. doi:10.1641/b571005

Oberritter H, Schäbethal K, von Ruesten A, Boeing H (2013) The DGE Nutrition Circle - presentation and basis of the food-related recommendations from the German Nutrition Society. Ernährungswiss Umsch Int 60(2):24-29

Oluoch MO, Pichop GN, Silué D, Abukutsa-Onyango MO, Diouf M, Shackleton CM (2009) Production and harvesting Systems for African indigenous vegetables. In: Pasquini CM, Drescher MW, Shackleton AW (eds) African indigenous vegetables in urban agriculture. Earthscan, London, pp 145-170
Orsini F, Kahane R, Nono-Womdim R, Gianquinto G (2013) Urban agriculture in the developing world: a review. Agron Sustain Dev 33:695-720. doi:10.1007/s13593-013-0143-z

Paradiso R, Meinen E, Snelb JFH, Visser PD, Ieperen WV, Hogewoning SW, Marcelis LFM (2011) Spectral dependence of photosynthesis and light absorptance in single leaves and canopy in rose. Sci Hortic 127:548-554

Säumel I, Kotsyuk I, Hölscher M, Lenkereit C, Weber F, Kowarik I (2012) How healthy is urban horticulture in high traffic areas? Trace metal concentrations in vegetable crops from plantings within inner city neighbourhoods in Berlin, Germany. Environ Pollut 162: 124-132. doi:10.1016/j.envpol.2012.02.019

Savidov NA, Hutchings E, Rakocy JE (2007) Fish and plant production in a recirculating aquaponic system: a new approach to sustainable agriculture in Canada. Acta Hortic (ISHS) 742:209-221

Savvas D, Passam H (2002) Hydroponic production of Vegetables and ornamentals. Embrio Publications, Athens, p 463

Schnell S (2013) Food miles, local eating, and community supported agriculture: putting local food in its place. Agric Hum Values 30: 615-628. doi:10.1007/s10460-013-9436-8

Shackleton CM, Pasquini MW, Drescher AW (2009) African indigenous vegetables in urban agriculture: recurring themes and policy lessons for the future. In: Drescher MW, Shackleton AW, Pasquini CM (eds) African indigenous vegetables in urban agriculture. Earthscan, London, pp 271-284

Smit J, Ratta A, Bernstein J (1996) Urban agriculture: food, jobs and sustainable cities. United Nations Developing Programme, New York, p 302

Specht K, Siebert R, Hartmann I, Freisinger UB, Sawicka M, Werner A, Thomaier S, Henckel D, Walk H, Dierich A (2013) Urban agriculture of the future: an overview of sustainability aspects of food production in and on buildings. Agric Hum Values Springer Science+Business Media Dordrecht. doi:10.1007/s10460-0139448-4

Taylor JR, Lovell ST (2012) Mapping public and private spaces of urban agriculture in Chicago through the analysis of high-resolution aerial images in Google Earth. Landsc Urban Plan 108:57-70. doi:10. 1016/j.landurbplan.2012.08.001

Taylor JR, Lovell ST (2014) Urban home food gardens in the Global North: research traditions and future directions. Agric Hum Values 31:285-305. doi:10.1007/s10460-013-9475-1

UNCCD (2012) Zero net land degradation. UNCCD, Bonn, pp 1-28

United Nations (2013) UN press release. http://esa.un.org/wpp/ Documentation/pdf/WPP2012 Press Release.pdf Accessed 7 February 2013

Vermeulen SJ, Aggarwal PK, Ainslie A, Angelone C, Campbell $\mathrm{BM}$, Challinor AJ, Hansen JW, Ingram JSI, Jarvis A, Kristjanson P, Lau C, Nelson GC, Thornton PK, Wollenberg E (2012) Options for support to agriculture and food security under climate change. Environ Sci Policy 15: 136-144. doi:10.1016/j.envsci.2011.09.003

Wheeler T, von Braun J (2013) Climate Change impacts on global food security. Science 134:508-513. doi:10.1126/science.1239402 